\title{
Punção aspirativa de medula óssea em eqüinos adultos para obtenção de células-tronco
}

\author{
Bone marrow aspiration in adult horses as a stem cell \\ obtention technique
}

\author{
Anna Paula Balesdent Barreira, ${ }^{*}{ }^{* *}$ Daniela Tendler Leibel Bacellar, ${ }^{*}$ Rosemberg Gomes Kiffer, ${ }^{*}$ Ana Liz Garcia Alves ${ }^{* *}$
}

\begin{abstract}
Resumo
Recentes estudos têm demonstrado potencial promissor na utilização das células-tronco em terapia de doenças degenerativas, de reparo lento ou ineficiente. A medula óssea é uma das fontes destas células em indivíduos adultos e seu isolamento é realizado por punção aspirativa. Este estudo teve como objetivo verificar a viabilidade da técnica de punção aspirativa de medula óssea em eqüinos sedados e mantidos em posição quadrupedal, como alternativa à utilização de anestesia geral e decúbito dorsal. No experimento, foram realizados aspirados de medula óssea em cinco eqüinos da raça Mangalarga Marchador, utilizando a identificação ultra-sonográfica das esternebras, preparo anti-séptico e posterior introdução de agulha Jamshidi. A amostra foi aspirada com seringa com anticoagulante, permitindo a realização de esfregaços, que, submetidos à microscopia, permitiram a identificação de sua origem, de medula óssea ou sangue periférico. Não foram descritos acidentes como perfuração pleural ou cardíaca, mas somente em duas das cinco amostras foram encontradas células provenientes da medula óssea. Este resultado demonstrou que a técnica é simples e, embora confiável, necessita de coletor treinado, a fim de otimizar resultados. Com o domínio da técnica será possível baixar risco e custo do procedimento, viabilizando a implementação da terapia celular em eqüinos, tanto experimental, quanto nas aplicações clínico-terapêuticas.
\end{abstract}

Palavras-chave: célula-tronco, punção aspirativa, medula óssea, eqüino.

\begin{abstract}
Recent studies have been demonstrating promissor results to the stem cells therapy of degenerative diseases as in cases of deficient healing process. In adults, the stem cells are found at bone marrow and their isolation could be accessed by aspiration technique. This study aims to evaluate a simple technique that enables adult horses stem cells collection, allowing further researches of cellular therapy in this species. The sternum is the site of choice for bone marrow aspiration in horses. Usually the animal is submitted to general anesthesia and it is positioned in dorsal recumbence. This experiment was developed in five Mangalarga Marchador horses. After ultrasonographic identification of $4^{\text {th }}$ sternebrae, the local was scrubbed and local anesthesia done. A Jamshidi biopsy needle was introduced and a sample was aspirated in a syringe with anticoagulant. Smears were immediately prepared and submitted to laboratory examination to verify its origin. No accidental pleural or cardiac perforation was reported but only two out of five samples were confirmed as bone marrow. This result demonstrates that the technique is simple and reliable, although needs to be improved and the collector trained to maximize results. As the knowledge is obtained, the stem-cell technologies can be implemented in this species.
\end{abstract}

Keywords: stem cell, aspiration, bone marrow, equine.

\section{Introdução}

Células-tronco (stem-cells) podem ser encontradas no embrião, no cordão umbilical, possivelmente na placenta e no indivíduo adulto. No adulto localizam-se em maior concentração na medula óssea, mas também como células-satélite nos tecidos e em pequenas quantidades até no sangue periférico. Por questões éticas e pela facilidade de obtenção, há tendência de utilização destas células do próprio indivíduo enfermo ou lesado, através de punção de medula óssea. A partir da descoberta do potencial de diferenciação destas células, tem sido explorada sua aplicação terapêutica, sob a forma de terapia celular ou da bioengenharia voltada para transplantes (Levenber et al., 2003).

Atualmente, a aplicação da terapia celular tem sido testada em animais com diversas enfermidades, mas as aplicações em lesões ortopédicas têm sido mais estudadas na espécie eqüina, como em grandes perdas ósseas (Muschler, Midura e Nakamoto, 2003), disfunções musculares (Chen e Goldhamer, 2003), recuperação de cartilagem (Fortier et al., 1998) e tendinites e desmites (Young et al., 1998; Smith et al., 2003; Thomas, 2004; Richardson et al., 2007).

\footnotetext{
* Faculdade de Medicina Veterinária da Universidade Castelo Branco, Av. Brasil, 9.727, CEP:21021-020, RJ, RJ. balesdent@castelobranco.br

** Depto. de Cirurgia, UNESP, Distrito de Rubião Jr., CEP: 18618-000, Botucatu, SP
} 
As indicações usuais para a punção aspirativa de medula óssea costumavam incluir determinados distúrbios hematopoiéticos e linfoproliferativos (Kathleen, 2000). Hoje, as indicações foram ampliadas, tendo em vista a presença de células-tronco na medula óssea e seu potencial terapêutico.

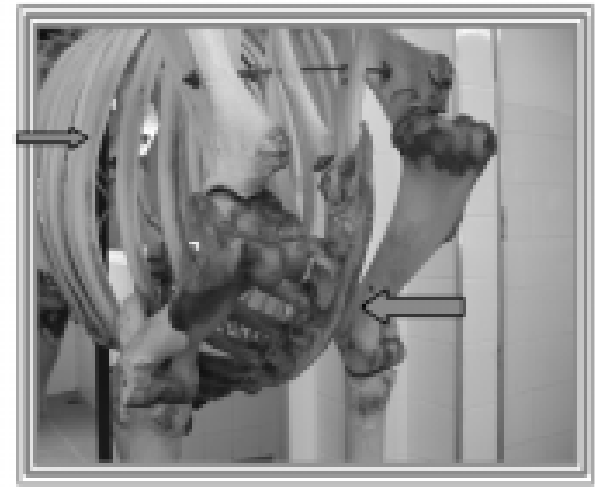

Figura 1: Esqueleto eqüino, sendo apontadas as possíveis áreas de punção aspirativa de medula óssea

Em eqüinos, o local utilizado com maior freqüência para a punção de medula óssea é o esterno, pois o osso é coberto por delgada massa muscular e a cavidade medular revestida por uma fina camada de osso, facilitando seu acesso. As desvantagens da punção deste local são a posição desconfortável e perigosa em que o coletor é forçado a assumir na obtenção das amostras e a relativa proximidade dos órgãos vitais, incluindo o coração (Speirs, 1999; Fortier et al., 1998; Thomas, 2004). Este osso, de localização torácica ventral (Figura 1), consiste em um número de seis segmentos ósseos, as esternebras, unidas por meio de cartilagem no indivíduo jovem (Sisson, 1975).

A medula óssea também pode ser coletada nas costelas de animais de grande porte, pois neste local a medula está disponível próxima à superfície do osso e o coletor se posiciona de forma segura durante o ato de punção. Entretanto, devido à superfície pequena e curvilínea da costela, há o risco do deslizamento da agulha e perfuração pleural (Rose, 1993).

Contrariando demais descrições sobre a técnica (Herthel, 2002 e Thomas, 2004), onde o eqüino é submetido à anestesia geral e decúbito dorsal, segundo Speirs (1999) e Smith et al. (2003), seria possível realizar a punção do esterno do eqüino com o animal em estação, submetido apenas à sedação. Em ambas as situações, a agulha é introduzida através da estabilização do osso e pressão firme, associada a movimentos de rotação na agulha. Uma vez firmemente assentado no osso, o mandril é removido e uma seringa de 10 a $20 \mathrm{~mL}$, com ou sem anticoagulante, utilizada para a aspiração. Aplica-se uma pressão negativa forte, a fim de prevenir a hemodiluição da amostra. A agulha da coleta deve ser deixada no local da seringa e o mandril recolocado enquanto os esfregaços são preparados. Uma vez que material suficiente tenha sido obtido, a agulha é removida, não sendo necessária sutura no local.

Contenção correta e tranqüilização dos eqüinos minimiza as possíveis complicações relacionadas com o procedimento. A preparação cirúrgica do local de punção, o uso de instrumentos esterilizados, luvas e técnicas de assepsia devem minimizar o risco de infecções iatrogênicas. Se o paciente tem anomalias de coagulação, como trombocitopenia ou coagulação intravascular disseminada, pode ocorrer hemorragia, a ser controlada por pressão direta no local por três a cinco minutos. Quando a punção do esterno ou costal é utilizada, deve-se ser cuidadoso ao introduzir a agulha, para evitar a entrada na cavidade torácica. O risco de pneumotórax, hemorragia grave ou laceração cardíaca pode ser diminuído pelo uso da vigilância e monitoria da agulha durante o procedimento (Morris, 1983), como também pela determinação do local ideal de punção com auxílio do ultra-som (Thomas, 2004).

Múltiplas lâminas devem ser obtidas, a fim de assegurar a aplicação das técnicas regulares e especiais na amostra. A medula é expelida diretamente numa lâmina de vidro limpa e rotulada, que ao ser inclinada, permite a eliminação da porção fluida e adesão das partículas de medula (Bartl, 1984; Kathleen, 2000).

Pode-se também expelir o material em placa Petri para avaliação e seleção das partículas de medula, sendo observadas como fragmentos cinzas, opacos, de formas irregulares e aderidas ao fundo da placa, distinguíveis de glóbulos de gordura claros, brilhosos e esféricos. As partículas de medula são transferidas para outra lâmina, permitindo realização do método de squash, com o cuidado de evitar pressão excessiva, que pode resultar em distorção ou ruptura das células (Russel, Sellon, Grindem, 1994; Kathleen, 2000).

As lâminas devem ser rapidamente secas ao ar para uma melhor manutenção da morfologia celular. Vários corantes, como o de Romanowsky ou Hematoxilina e Eosina, podem ser utilizados na avaliação de rotina da medula óssea. A concentração dos corantes precisa ser aumentada quando comparada àquela utilizada para corar esfregaços de sangue periférico, sendo dependente da celularidade do aspirado de medula óssea e da espessura dos esfregaços (Bartl, 1984; Russel, Sellon, Grindem, 1994; Kathleen, 2000).

Este estudo teve como objetivo avaliar técnica simples de punção aspirativa de medula óssea em esterno de eqüinos mantidos em estação, permitindo, assim, a obtenção de células-tronco e, conseqüentemente, fomentar sua pesquisa e aplicação na Medicina Veterinária.

\section{Material e métodos}

Foram escolhidos aleatoriamente cinco animais da raça Mangalarga Marchador, dentre uma população de um haras do município de Miguel Pereira, Rio de Janeiro, submetidos à semelhante manejo alimentar, condições sanitárias e exercício. Os animais apresentavam idade de três a nove anos, de ambos os sexos e hígidos.

Como preparo para a punção, houve tricotomia na região esternal, desde a região cranial do manúbrio até a cartilagem xifóide. Para execução do exame sonográfico foi utilizado o equipamento portátil da marca GE modelo Logic $\alpha-100$, provido de transdutor linear convexo de $5,0 \mathrm{MHz}$. A varredura foi executada obliquamente à linha média do esterno, permitindo a localização da 3a e 4a esternebra e em seguida, realizada a marcação do local de punção e posterior anti-sepsia.

A sedação foi realizada com romifidina ${ }^{1}(0,8 \mathrm{~mL} / 100 \mathrm{Kg})$, por via intravenosa, sendo mantido o animal em posição

\footnotetext{
${ }^{1}$ Sedivet - Boehringer Ingelheim
} 
quadrupedal no brete. O bloqueio anestésico foi realizado com cloridrato de lidocaína a $2 \%$, sem vasoconstritor, sendo feito infiltrado subcutâneo, intramuscular e próximo ao periósteo. Em seguida, foi introduzida agulha Jamshid (calibre 8 e $15 \mathrm{~cm}$ de comprimento), penetrando na musculatura por uma profundidade de $4-6 \mathrm{~cm}$ até chegar na superfície da esternebra. Após sentir-se a superfície óssea na extremidade da agulha faz-se pressão sobre a mesma, a fim de permitir sua penetração por mais $4-5 \mathrm{~cm}$, até a agulha ficar firme (Figura 2). Uma vez bem fixa a agulha, realiza-se a aspiração nas células da medula óssea com auxílio de uma seringa de $20 \mathrm{ml}$ heparinizada (1000 Ul/mL). Para cada amostra obtida foram preparados cinco esfregaços, do tipo squash, que foram encaminhados ao laboratório de patologia clínica para confirmação da origem do material, isto é, medula óssea ou sangue periférico.

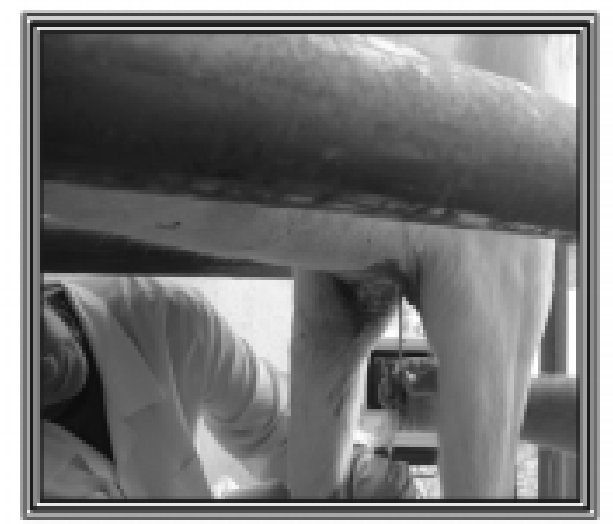

Figura 2: Técnica de punção aspirativa de medula óssea no externo

No Laboratório de Patologia Clínica do Curso de Medicina Veterinária da Universidade Castelo Branco, as amostras foram coradas pelo método de Romanowsky e avaliadas ao microscópio óptico, quanto à presença de precursores hematopoiéticos. A presença dos mesmos indica a obtenção de amostra de medula óssea, enquanto a predominância de hemácias e células maduras indica tratar-se de amostra de sangue periférico.

\section{Resultados e discussão}

A sedação adotada mostrou-se eficiente na contenção para tal procedimento. Apesar do tamanho da agulha e da extensa penetração no tecido ósseo, não foi observada manifestação de dor, sugerindo a eficácia do bloqueio anestésico aliado à sedação. No entanto, para avaliação adequada na mensuração da dor, seria necessário monitorar a freqüência cardíaca e níveis de cortisol do animal.

Observou-se que a técnica de punção de medula óssea em esterno de eqüinos mantidos em estação, como citado por Speirs (1999) e descrito por Thomas (2004) é viável, apesar do desconforto causado ao coletor, devido à posição em relação ao animal e a força em sentido ventro-dorsal necessária para a penetração da agulha. Por isto, há necessidade de treinamento do coletor. A viabilidade da realização desta técnica deve ser ressaltada neste projeto, uma vez que os trabalhos desenvolvidos por Herthel (2002) e Smith e colaboradores (2003) foram desenvolvidos com animais mantidos em decúbito dorsal e sob anestesia geral, o que gera maior risco e custo para a técnica.

A punção realizada no animal mais jovem do grupo, com três anos de idade, apresentou maior facilidade de penetração da agulha, enquanto no animal mais idoso, com nove anos, a penetração revelou maior dificuldade. Esta diferença pode ser explicada pelos diferentes estágios de mineralização do esqueleto, resultando em menor ou maior facilidade na execução da técnica. Entretanto, apesar da facilidade de penetração da agulha no animal jovem, foi obtida amostra de apenas $1,5 \mathrm{~mL}$ após inúmeros bombeamentos, enquanto no animal adulto a amostra foi mais abundante $(5 \mathrm{~mL})$, sugerindo maior cavidade medular. Os demais animais apresentaram resistência intermediária na penetração da agulha e as amostras obtidas continham cerca de $0,5 \mathrm{~mL}$.

Apesar das particularidades descritas, coletou-se amostra em quantidade suficiente $(0,5$ a $5,0 \mathrm{~mL})$ dos 5 animais submetidos à punção de apenas um local, porém caso a amostra fosse ser submetida à cultura para expansão da população de células-tronco, como realizada por Smith et al. (2003), seria necessário considerar a punção de diversos sítios.

A aparência macroscópica das amostras obtidas em três dos cinco animais era semelhante, sendo caracterizada por sangue de coloração levemente clara, com gotículas de gordura e pela presença de pequenos grânulos acinzentados, como descrito por Car e Blue (2000). Entretanto, em apenas duas das cinco amostras foi confirmada a origem medular. As demais amostras apresentavam coloração mais escura e a ausência de gordura ou grânulos, e, ao serem avaliadas pela microscopia, confirmou-se apenas a presença de sangue periférico. A análise microscópica teve apenas a função de identificar, através da morfologia, as células imaturas características de medula óssea (Figura 3). Uma vez confirmada a origem medular, considera-se a presença de células-tronco de diversas linhagens dentre sua população.

Figura 3: Sangue periférico, composto por hemácias e células maduras (à esq.). Sangue de medula óssea, com células imaturas (à dir.).
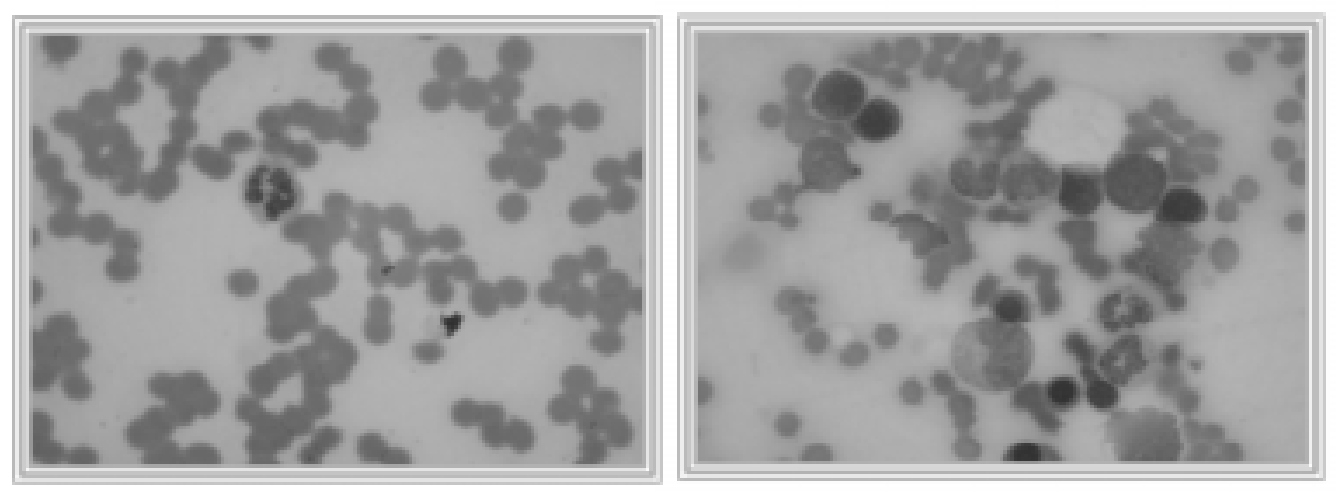


\section{Conclusões}

Baseado na obtenção de material de medula óssea em dois dos cinco animais puncionados neste trabalho, pode-se confirmar a viabilidade desta técnica com animal mantido em posição quadrupedal, ressaltando seu baixo custo e menor risco ao animal. Ao divulgar esta técnica simplificada,

\section{Referências}

BARTL, R.; FRISCH, B. E Multiparameter studies on 650 bone marrow biopsy cores. Diagnostic value of combined utilization of imprints, cryostat, and plastic sections in medical pratice. Bibl Haematol, v. 50, p. 1-16, 1984.

CAR, B.D.; BLUE, J.T. Punção aspirativa e biópsia de medulla óssea. In: FELDMAN, B.F.;ZINKL, J.G.; JAIN, N.C. Schalm's Veterinary Hematology $4^{\text {th }}$ ed. Philadelphia:Lipencott Williams e Wilkins, 2000, cap. 4, p.18-29.

CHEN, JCJ e GOLDHAMER, D.J. Skeletal muscle stem cells. Reproductive Biology and Endocrinology. Disponível em http:// www.rbej.com/content/1/1/101. 2003.

FORTIER, A.L.; NIXON, A.J.; WILLIAMS, J.; CABLE, C.S. Isolation and chondrocytic differentiation of equine bone marrow-derived mesenchymal stem cells. AVRJ. v. 59, n. 9, p. 1182-1187, 1998.

HERTHEL, D.J. Suspensory desmitis therapies equine Proceedings of ACVS Veterinary Symposium, San Diego, California. Outubro, 2002.

KATHELEEN P.F. Bone marrow evaluation..In: FELDMAN, B.F.; ZINKL, J.G.; JAIN, N.C. Schalm's Veterinary Hematology. Cap. 5, p. 29-32, 2000.

LEVENBERG, S.; HUANG, N.F.; ROGERS, A.B.; ITSKOVITZ-ELDOR, J.; LANGER, R. Differentiation of human embryonic stem cells on threedimensional polymer scaffolds. Proc. Nat. Acad. Sci. USA, v. 10, n. 22, 2003.

MORRIS D.D.; WHITLOCK R.H. Relapsing idiopathic thrombocytopenia in a horse. Equine Vet J., v. 15, p. 73-75, 1983. acreditamos tornar possível o acesso à medicina regenerativa aos profissionais localizados a campo. Apesar da viabilidade, deve ser relatada a dificuldade de posicionamento do coletor ao realizar a punção de medula óssea, sendo importante o seu treinamento. Estudos futuros devem ser desenvolvidos, tendo em vista o pequeno número de animais utilizados no atual estudo, em relação à população eqüina como um todo.

MUSCHLER, G.F.; MIDURA, R.J.; NAKAMOTO, C. Practical modeling concepts for connective tissue stem cell and progenitor compartment kinetics Journal of Biomedicine and Biotechnology, v. 3, 2003. p. $170-$ 193.

RICHARDSON, L.E.; DUDHIA, J.; CLEGG, P.D.; SMITH, R. Stem cells in veterinary medicine - attempts at regenerating equine tendon after injury. Trends in Biotechnology. 2007. Disponível em http:// www.sciencedirect.com

ROSE, R.J.; HODGSON D.R. Manual of Equine Pratice. 2. ed. Philadelphia: W.B. Saunders. 330 p., 1993.

RUSSEL, K.E.; SELLON, D.C.; GRINDEM, C.B. Bone Marrow in horses: indications, sample handling and complications. The Compendium, v. 16, n. 10, p. 1359-1366, 1994.

SISSON, S. e Grossman, J.D. Anatomía de los animales domésticos. 12. ed. Barcelona: Salvat Editores, 1975.

SMITH. R. K. W.; KORDAM.; BLUNNG. W. and A. E.GOODSHIP. Isolation and implantation of autologous equine mesenchymal stem cells from bone marrow into the superficial digital flexor tendon as a potential novel treatment. Equine Veterinary Journal, London, p. 9-102, 2003. SPEIRS, V.C. Exame clínico de eqüinos. Porto Alegre: Artmed, p. 319321, 1999.

THOMAS, HS Mending with marrow. The Horse. Dez., p. 53-56, 2004. YOUNG R.G.; BUTLER D.L.; W. WEBER, CAPLAN A.I.; GORDON S.L. and FINK D.J. Use of mesenchymal stem cells in a collangen matrix for achilles tendon repair, Journal of Orthopaedic Research, v. 16, n. 4, p. 406-413, 1998. 